\title{
Population Growth and Allergen Content of Cultured Euroglyphus maynei House Dust Mites
}

\author{
Marjorie S. Morgan DiAnn L. Vyszenski-Moher Larry G. Arlian \\ Department of Biological Sciences, Wright State University, Dayton, Ohio, USA
}

\section{Key Words}

Euroglyphus maynei. House dust mite · Population growth . Allergen · Endotoxin

\begin{abstract}
Background: The house dust mite, Euroglyphus maynei, occurs in homes worldwide and is an important source of many allergens. Many patients sensitive to Dermatophagoides farinae and $D$. pteronyssinus are also sensitive to E. maynei. Extracts to detect sensitivity to $E$. maynei and reagents to detect $E$. maynei allergens in the environment or in cultures are not readily available. Information for the culture of $E$. maynei and for the determination of allergen and endotoxin levels in cultures is limited. Method: We mass cultured E. maynei at 23 and $30^{\circ} \mathrm{C}$ and determined the population growth profiles from inoculation until cultures could be harvested for the production of extracts. We also developed an ELISA to measure Eur $\mathrm{m} 1$ and Eur $\mathrm{m} 2$ allergens using mouse monoclonal antibodies directed at cross-reacting epitopes of group 1 and group 2 allergens of $D$. farinae and $D$. pteronyssinus. Results: The E. maynei populations grew exponentially at both 23 and $30^{\circ} \mathrm{C}$; however, the cultures matured more rapidly at $23^{\circ} \mathrm{C}$. The Eur $\mathrm{m} 1$ and Eur $\mathrm{m} 2$ allergen concentrations in culture extracts changed independently as the cultures grew and matured. At both temperatures, the Eur $\mathrm{m} 1$ concentrations increased as the cultures matured, while the Eur
\end{abstract}

$\mathrm{m} 2$ concentrations did not. The endotoxin levels in these cultures were low. Conclusion: We report here that $E$. maynei can be cultured at 23 and $30^{\circ} \mathrm{C}$. Monoclonal antibodies directed at cross-reacting epitopes on Dermatophagoides allergens can be used to measure the associated E. maynei allergen levels in these cultures.

(c) 2015 S. Karger AG, Basel

\section{Introduction}

The house dust mites, Euroglyphus maynei, Dermatophagoides farinae and D. pteronyssinus, in the family Pyroglyphidae occur in homes worldwide. E. maynei frequently co-inhabits with $D$. farinae and $D$. pteronyssinus in some geographical areas, and in some instances E. maynei may be the more abundant species [1-12]. Many dust mite allergic patients are skin test positive to all 3 species of these mites [13-16].

E. maynei is the source of many allergens. Some E. may$n e i$ allergens are species-specific, but some are cross-reactive with allergens of $D$. farinae and $D$. pteronyssinus and of other mite species [14, 17-21]. Few of the many allergens from E. maynei have been characterized compared to those from $D$. farinae and $D$. pteronyssinus $[7,22,23]$, and no commercial assays for monitoring their levels in mite cultures or extracts are currently commercially available.

\section{KARGER 125}

(c) 2015 S. Karger AG, Base

$1018-2438 / 15 / 1664-0267 \$ 39.50 / 0$ 
D. farinae and $D$. pteronyssinus are widely cultured for research and commercial purposes, but E. maynei is not and is generally not commercially available, especially in the US. The population growth and associated allergen and endotoxin profiles of cultured D. farinae and D. pteronyssinus have been described [24-35]. However, there are little data that characterize the population growth in cultured E. maynei mites and the parallel allergen production and endotoxin accumulation in these cultures. Additional allergen and endotoxin data are needed for cultured E. maynei in order to develop culture conditions suitable to obtain mite material to make extracts for research, diagnostic and immunotherapeutic purposes.

We report here the development of assays to monitor 2 allergens (Eur m 1 and Eur m 2) in E. maynei culture extracts using commercially available reagents developed to detect Dermatophagoides group 1 and group 2 allergens. We also studied the population growth characteristics of E. maynei cultured at 2 temperatures $\left(23\right.$ and $\left.30^{\circ} \mathrm{C}\right)$ and used our assays to monitor the associated allergen accumulation in the mite cultures as they matured to the point when mite material for extract preparation could be harvested.

\section{Materials and Methods}

\section{Stock Cultures}

Laboratory stock cultures that had been maintained for many years were the source of E. maynei for these studies. These stock cultures had been grown on media consisting of a mixture (9:1, $\mathrm{v} / \mathrm{v}$ ) of dried raw whole egg powder (Product No. 1190, Bio-Serv Inc., Frenchtown, N.J., USA) and granular baker's yeast (Fleischmann's Active Dry Yeast No. 2192, AB Mauri Foods, Chesterfield, Mo., USA) at $75 \%$ relative humidity $(\mathrm{RH})$ and room temperature $\left(20-23^{\circ} \mathrm{C}\right)$.

\section{Population Growth at 23 and $30^{\circ} \mathrm{C}$ (Experiment No. 1)}

The methods used for these studies were similar to those previously described for $D$. farinae and D. pteronyssinus [24-26]. Briefly, 5 replicate test cultures were started in one-cup glass Ball ${ }^{\circledR}$ jars (Cat. No. 14400-6500, Alltrista Corp., Indianapolis, Ind., USA) by inoculating $30 \mathrm{~g}$ of culture medium with $6 \mathrm{~g}$ of well-mixed thriving culture for the experiments at $23^{\circ} \mathrm{C}$ and by adding $3 \mathrm{~g}$ of thriving culture to $15 \mathrm{~g}$ of diet for the experiments at $30^{\circ} \mathrm{C}$. The cultures used for inoculation had previously been grown at room temperature. These inoculated test cultures were thoroughly mixed, and the jars with inoculum and diet were capped with plastic lids (Cat. No. 14400-37000, Jardan Home Brands, Daleville, Ind., USA) and placed in a humidity chamber (33 cup Rubbermaid Servin' Saver No. 8, Rubbermaid Commercial Products, Winchester, Va., USA) maintained at $75 \% \mathrm{RH}$ using saturated $\mathrm{NaCl}$ solution that was held in a temperature-controlled incubator (Model 307C, Fisher Scientific, Pittsburgh, Pa., USA). Both the jar and the chamber lids were ventilated with a $2.5-\mathrm{cm}$ circular hole covered with $35-\mu \mathrm{m}$ nylon mesh (Cat. No. B-CMN-35, Small Parts Inc., Miami Lakes, Fla., USA) sealed in place with Shoe Goo (Eclectic Products, Inc., Pineville, La., USA). At the time of inoculation $(t=0)$ and every 2 weeks thereafter, the test cultures were mixed, and duplicate weighed samples of the culture material (10-50 mg) were removed from each of the 5 cultures and placed into a gridded petri dish, and the numbers of live mites (all mobile life stages) were counted using a stereomicroscope. All mite counts were normalized to mites/100 mg of culture material.

\section{Population Growth at $30^{\circ} \mathrm{C}$ after Acclimation at $30^{\circ} \mathrm{C}$}

(Experiment No. 2)

Based on the results of experiment No. 1, we repeated the $30^{\circ} \mathrm{C}$ culturing experiment using stock cultures that had been acclimated at $30^{\circ} \mathrm{C}$ for 12 weeks. As before, 5 jars each containing $15 \mathrm{~g}$ of food were inoculated with $3 \mathrm{~g}$ of thriving culture material from the acclimated stock cultures. At inoculation and at weekly intervals, 1 weighed aliquot of culture material was removed from each of the 5 well-mixed culture jars, and the numbers of live mites were counted and the counts normalized to mites/100 mg culture as before.

\section{Biochemical Analyses (Protein, Endotoxin and Allergen)}

At each sampling time during the growth of the cultures in experiment No. 1, aliquots of $\sim 100 \mathrm{mg}$ of whole culture material were removed from each of the well-mixed cultures and frozen in 5-ml microtubes (T2076A, Argos Technologies, Elgin, Ill., USA) for allergen and endotoxin analyses at the end of the experiment. After all samples were collected, aqueous extracts were prepared, and the protein and endotoxin contents were determined as previously described [24-26]. Briefly, aliquots of culture from each sample were extracted overnight at $4^{\circ} \mathrm{C}$ at $50.0 \mathrm{mg} / \mathrm{ml}$ in endotoxin-free water (Cat. No. W50-500, Lonza, Walkersville, Md., USA). The next day, samples were sonicated on ice for $10 \mathrm{~min}$ (FS20 Bath Sonicator, Fisher Scientific), and aliquots were transferred to 1.5$\mathrm{ml}$ microfuge tubes (Protein LoBind 022431081, Eppendorf NA, Westbury, N.Y., USA) and then microfuged at $4{ }^{\circ} \mathrm{C}$ for $10 \mathrm{~min}$ at $14,000 \mathrm{~g}$. The supernatants were collected, and a NanoDrop 1000 spectrophotometer (Thermo Scientific, Pittsburgh, Pa., USA) was used to determine the protein concentrations using the 'Abs = $1 \mathrm{mg} / \mathrm{ml}$ ' settings in the 'Protein A280' module. A QCL-1000 endotoxin test kit (Lonza) was used as prescribed to determine the amount of endotoxin in each sample aliquot.

Enzyme-linked immunosorbent assays (ELISAs) were developed to determine the amounts of group 1 and group 2 allergen in the aqueous culture extracts. Assay plates (Costar 3590, Corning Inc., Corning, N.Y., USA) were coated at $1 / 1,000$ in $50 \mathrm{~mm}$ carbonate/bicarbonate buffer, pH 9.6 (Cat. No. C-3041, Sigma-Aldrich Co., St. Louis, Mo., USA) with a mouse monoclonal antibody. Antibody 4C1 (MA-4C1, Indoor Biotechnologies, Charlottesville, Va., USA), that binds to a common epitope on mite group 1 allergens, was used to capture Eur $\mathrm{m} 1$, while an antibody raised against Der p 2 (MA-1D8, Indoor Biotechnologies) was used to capture Eur $\mathrm{m} 2$. The capture antibody was allowed to bind overnight at $4^{\circ} \mathrm{C}$, and the plates were washed after this and every step. The wash (PBST) was composed of Dulbecco's phosphate buffered saline (Sigma D5652-50L) containing 0.05\% Tween 20 (Fisher BP-337500 ). PBST with $1 \%$ bovine serum albumin (Fisher BP-1600-100) was used as block and diluent. The samples were serially diluted and incubated on the test plate for $2 \mathrm{~h}$ at room temperature. Fol- 


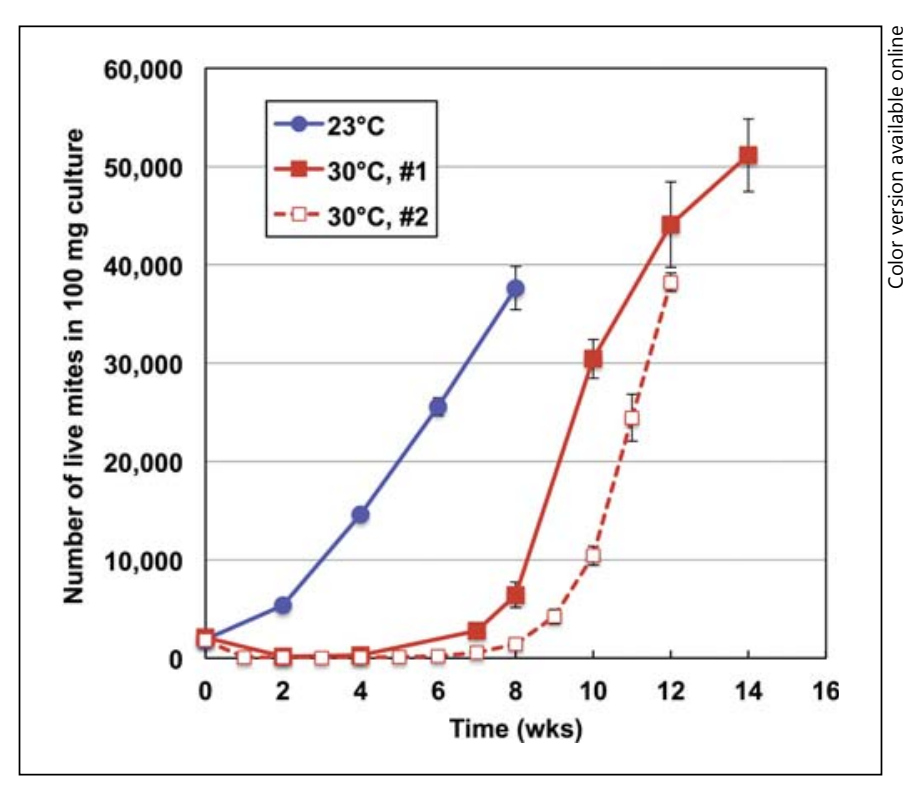

Fig. 1. Population growth of E. maynei at 2 different growth temperatures. Growth at $30^{\circ} \mathrm{C}$ was determined twice.

lowing the washing, the plates were incubated for $1 \mathrm{~h}$ with rabbit antiserum to E. maynei whole body extract [17] diluted at $1 / 2,000$. Mouse-adsorbed, peroxidase-labeled, goat antirabbit IgG (Cat. No. 4050-05, Southern Biotech, Birmingham, Ala., USA) at $1 / 5,000$ for $1 \mathrm{~h}$ was used as detecting antibody. The plates were developed with $100 \mu \mathrm{l}$ of $1 \mathrm{~mm} \mathrm{ABTS}$ (Sigma A1888) in $70 \mathrm{~mm}$ citrate phosphate buffer, $\mathrm{pH} 4.0$, with $0.03 \%$ hydrogen peroxide (Sigma H1009). Development was stopped at 5:00 min for Eur $\mathrm{m} 1$ and at 7:00 min for Eur $\mathrm{m} 2$ by the addition of $50 \mu \mathrm{l}$ of $0.2 \%$ sodium azide, and the plates were read immediately using an ELx800 microtiter plate reader (Bio-Tek Instruments, Winooski, Vt., USA). Data are presented as the absorbance at $405 \mathrm{~nm}$ of samples diluted at 1/400.

\section{Results}

\section{Population Growth}

E. maynei populations grew exponentially at both 23 and $30^{\circ} \mathrm{C}$ until the experiment was stopped or the diet was consumed and became limiting (fig. 1). However, the growth profiles at the 2 temperatures were very different. At $23^{\circ} \mathrm{C}$, the population growth began immediately, and the population size had increased about 3 times during the first 2 weeks of population growth, and by 8 weeks it had increased 20 -fold compared to the mite density at the time of inoculation $(t=0)$. In contrast, the cultures grown at $30^{\circ} \mathrm{C}$ exhibited a $>90 \%$ decline in the numbers of live mites within 2-3 weeks of the inoculation. This was followed by an exponential growth with a lag of 7 weeks.

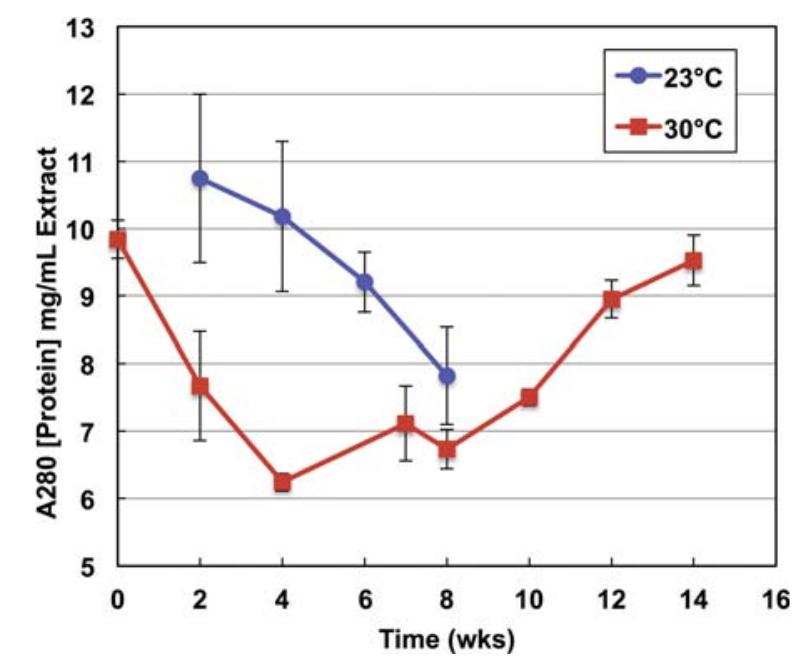

Fig. 2. Protein concentrations in aqueous extracts prepared from E. maynei cultures grown at 2 different temperatures.

This was observed both in the cultures inoculated with mites that had been grown at room temperature $\left(30^{\circ} \mathrm{C}\right.$, experiment No. 1) and in the cultures inoculated with mites that had been acclimated to $30^{\circ} \mathrm{C}$ for 12 weeks prior to the inoculation $\left(30^{\circ} \mathrm{C}\right.$, experiment No. 2). After 12 weeks of culture at $30^{\circ} \mathrm{C}$, the population densities of both sets of cultures also increased 20 -fold compared to the starting mite density $(t=0)$. Thus, the peak population densities for all cultures were similar, regardless of the rearing temperature.

\section{Protein and Allergen Concentrations}

The amount of water-soluble protein that could be extracted from $50 \mathrm{mg}$ of culture material declined constantly in the cultures held at $23^{\circ} \mathrm{C}$, even though thriving mite populations developed (fig. 2). Over this same time, the Eur $\mathrm{m} 1$ concentrations in these extracts steadily increased, while the Eur $\mathrm{m} 2$ concentrations declined slightly (fig. 3).

At $30^{\circ} \mathrm{C}$, the protein concentrations in the aqueous extracts initially declined but then returned to the initial levels after 14 weeks when the cultures had reached maturity (fig. 2). The Eur $\mathrm{m} 1$ concentration profile in the $30^{\circ} \mathrm{C}$ culture extracts paralleled the live mite population growth, increasing over time (fig. 3). The Eur m 2 concentrations in the extracts declined during the first 4 weeks of culturing but then returned to the initial levels when the cultures matured. 


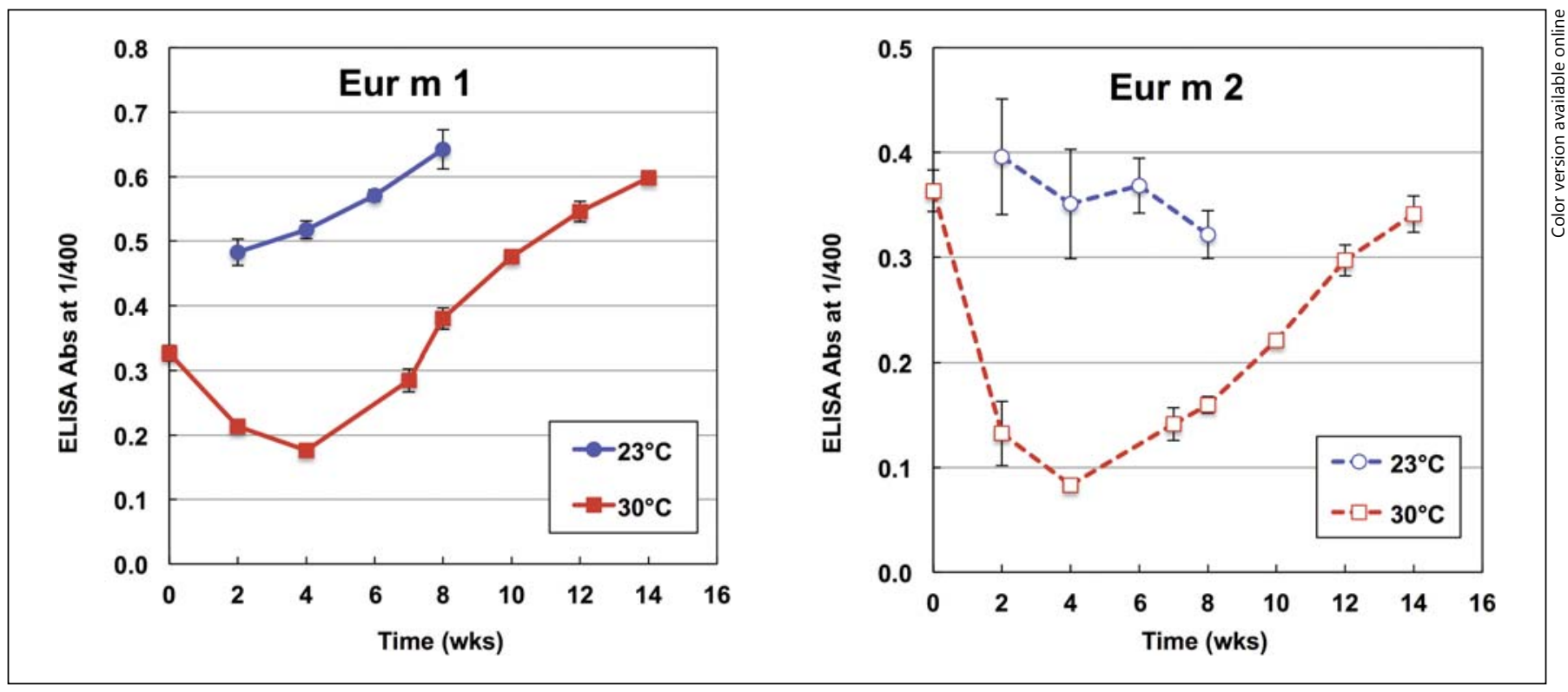

Fig. 3. Eur $\mathrm{m} 1$ and Eur $\mathrm{m} 2$ allergen concentrations in aqueous extracts prepared from E. maynei cultures grown at 2 different temperatures.

\section{Endotoxin Levels}

The endotoxin levels in the aqueous extracts of the cultures grown at both 23 and $30^{\circ} \mathrm{C}$ were low $(<105 \mathrm{EU} / \mathrm{ml}$ extract) but did trend upward during the 8 and 14 weeks of mite population growth, even though the cultures were thriving and most media were depleted (fig. 4).

\section{Discussion}

Extracts of E. maynei for diagnosis and immunotherapy are not commercially available in the US and many parts of the world. Little is known about methods for mass culture and the associated allergen production in E. maynei mite cultures. This is in large part due to the fact that no assays are currently available to measure allergen levels in culture extracts. We began our studies by developing ELISAs to monitor the levels of group 1 (Eur $\mathrm{m} 1$ ) and group 2 (Eur $\mathrm{m} 2$ ) allergens in aqueous extracts of $E$. maynei cultures.

The E. maynei group 1 allergen, Eur $\mathrm{m} 1$, is a $25 \mathrm{kDa}$ protein that shares about $85 \%$ sequence homology with Der $\mathrm{p} 1$ and Der $\mathrm{f} 1$, the group 1 allergens of $D$. pteronyssinus and $D$. farinae, respectively $[36,37]$. The group 2 allergens of the 3 species are $14 \mathrm{kDa}$ proteins, and Eur m 2 shares about $83 \%$ amino acid sequence homology with Der $\mathrm{p} 2$ and Der $\mathrm{f} 2[37,38]$. It therefore seemed likely that a monoclonal antibody raised against $\operatorname{Der} \mathrm{f} 1$, that recog-

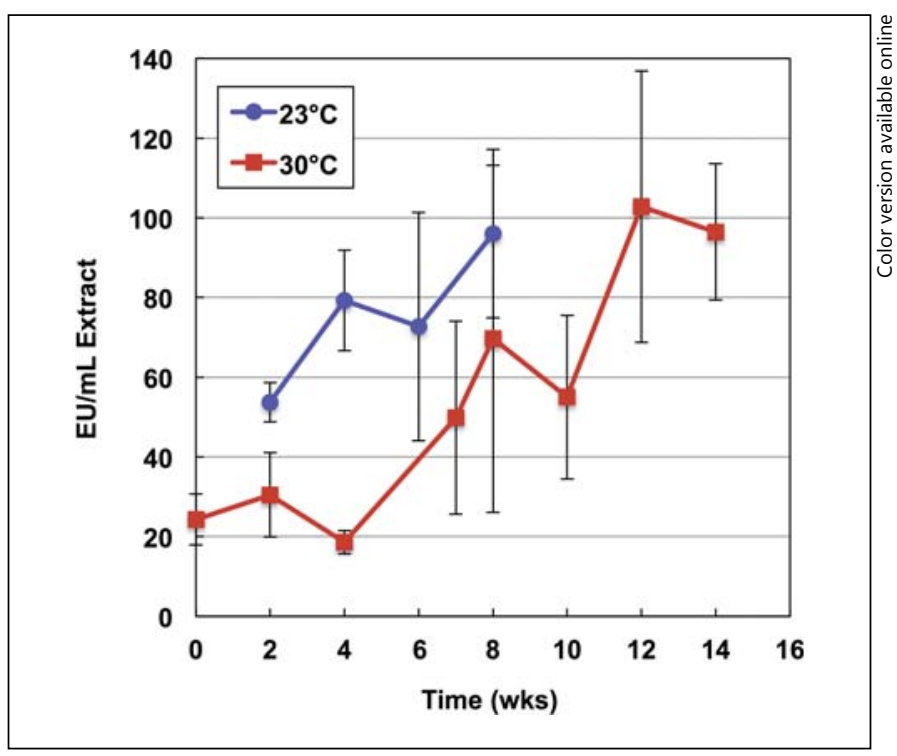

Fig. 4. Endotoxin concentrations in aqueous extracts prepared from E. maynei cultures grown at 2 different temperatures.

nizes a common epitope on Der p 1 (Indoor Biotechnologies antibody MA-4C1; [39]) would also bind to Eur $\mathrm{m} 1$. Likewise, an antigroup 2 monoclonal antibody (Indoor Biotechnologies antibody MA-1D8; [40]) would also bind to Eur $\mathrm{m} 2$ from E. maynei. Therefore, we used these monoclonal antibodies to capture the E. maynei allergens, Eur $\mathrm{m} 1$ and Eur $\mathrm{m} 2$, from aqueous extracts of mite 
culture materials. Polyclonal antiserum previously raised against E. maynei whole body extract [17], followed by peroxidase-labeled goat antirabbit IgG and development with a chromogenic peroxidase substrate, allowed for the detection and relative quantitation of the 2 individual E. maynei allergens.

\section{Population Growth}

We observed that establishing thriving laboratory cultures and the population growth of E. maynei in these cultures were influenced by temperature, and this needs to be considered when culturing this mite species for research and medical purposes. At $23^{\circ} \mathrm{C}$, the mite population immediately expanded exponentially from the time the cultures were inoculated until they reached maturity and were terminated 8 weeks later. Similar growth profiles for D. farinae and D. pteronyssinus cultures have been reported [24-30].

In contrast, at $30^{\circ} \mathrm{C}$, there was a lag in the population growth of E. maynei before exponential growth was apparent. It was not clear what caused this lag in the population growth. It could have been due to the fact that the first set of $30^{\circ} \mathrm{C}$ cultures were initiated with mites from stock cultures that had been maintained at $75 \% \mathrm{RH}$ and at a room temperature of approximately $21-22^{\circ} \mathrm{C}$ for years. The switch to $30^{\circ} \mathrm{C}$ may have required time to select for mites genetically adapted for better survival and reproduction at the higher temperature which occurred over the lag period before the population expanded exponentially. We hypothesized that this lag time might be reduced by inoculating new cultures with mites taken from thriving cultures that had been acclimated at $30^{\circ} \mathrm{C}$ for several months. This allowed sufficient time for 6 generations of mites to grow under these conditions [36]. Thriving mite material from this acclimated culture was then used to inoculate new cultures that were again held at $30^{\circ} \mathrm{C}$ (experiment No. 2). The lag in population growth again occurred before exponential growth was apparent. Thus, given the long time required to develop mature cultures of E. maynei at $30^{\circ} \mathrm{C}$, it appears that at $75 \% \mathrm{RH}$, $23^{\circ} \mathrm{C}$ is the better temperature for the mass culturing of E. maynei to produce material for extracts that can be used for research, diagnosis and therapy purposes.

\section{Allergen Levels in E. maynei Culture Extracts}

Using our newly developed ELISAs, we were then able to monitor the levels of group 1 and group 2 allergen in aqueous extracts of the E. maynei cultures. At both culture temperatures, the Eur $\mathrm{m} 1$ levels paralleled the mite population growth profiles. In contrast, the Eur $\mathrm{m} 2$ al- lergen levels in extracts of the $23^{\circ} \mathrm{C}$ cultures remained relatively constant over the 8 -week culture period, while in extracts of the cultures grown at $30^{\circ} \mathrm{C}$ the level of this allergen declined before eventually rebounding to $t=0$ levels. This suggests that allergen degradation may be occurring in the $30^{\circ} \mathrm{C}$ cultures. This is in agreement with an earlier report that allergen decay was enhanced in a warm, humid environment [41].

\section{Endotoxin Levels}

Endotoxin concentrations in the cultures grown at both 23 and $30^{\circ} \mathrm{C}$ were very low $(<105 \mathrm{EU} / \mathrm{ml}$ extract) throughout the experiment. This was surprising since $D$. farinae and $D$. pteronyssinus cultures grown on the same diet at room temperature $\left(19.6-21.8^{\circ} \mathrm{C}\right)$ had endotoxin concentrations of 526,380 and $8,440 \mathrm{EU} / \mathrm{ml}$ extract, respectively, at the peak of culture growth [24].

\section{Conclusions}

This study clearly shows that E. maynei can be cultured on the same diet and at the same climatic conditions that supports long-term cultures of D. farinae and D. pteronyssinus. However, thriving cultures of E. maynei clearly develop better at $23^{\circ} \mathrm{C}$ than at $30^{\circ} \mathrm{C}$. The population growth, allergen production and endotoxin in the cultures of E. maynei presented in this study can now be compared to similar data for the Dermatophagoides species [24-30, 42, 43]. The results of our study will be useful to those interested in establishing long-term cultures of E. maynei for research and commercial purposes.

\section{Acknowledgments}

The authors would like to thank Dr. Martin D. Chapman for his helpful suggestions.

References

Int Arch Allergy Immunol 2015;166:267-272 271
1 Arlian LG, Bernstein D, Bernstein IL, et al: Prevalence of dust mites in the homes of people with asthma living in eight different geographic areas of the United States. J Allergy Clin Immunol 1992;90:292-300.

2 Arlian LG, Morgan MS: Biology, ecology, and prevalence of dust mites. Immunol Allergy Clin North Am 2003;23:443-468.

3 Blythe ME, Williams JD, Smith JM: Distribution of pyroglyphid mites in Birmingham with particular reference to Euroglyphus maynei. Clin Allergy 1974;4:25-33. 
4 Boquete M, Iraola V, Fernandez-Caldas E, et al: House dust mite species and allergen levels in Galicia, Spain: a cross-sectional, multicenter, comparative study. J Investig Allergol Clin Immunol 2006;16:169-176.

5 Charlet LD, Mulla MS, Sanchez-Medina M: Domestic Acari of Colombia: population trends of house dust mites (Acari: Pyroglyphidae) in homes in Bogota, Columbia. Int I Acarol 1978;4:23-32.

6 Colloff MJ: A review of the biology and allergenicity of the house-dust mite Euroglyphus maynei (Acari: Pyroglyphidae) (corrected). Exp Appl Acarol 1991;11:177-198.

7 Colloff M: Dust Mites. Collingwood, CSIRO, 2009.

8 Fernandez-Caldas E, Fox RW, Bucholtz GA, Trudeau WL, Ledford DK, Lockey RF: House dust mite allergy in Florida. Mite survey in households of mite-sensitive individuals in Tampa, Florida. Allergy Proc 1990;11:263267.

9 Mumcuoglu Y: House dust mites in Switzerland. I. Distribution and taxonomy. J Med Entomol 1976;13:361-373.

10 Smith TF, Kelly LB, Heymann PW, Wilkins SR, Platts-Mills TA: Natural exposure and serum antibodies to house dust mite of miteallergic children with asthma in Atlanta. J Allergy Clin Immunol 1985;76:782-788.

11 Valdivieso R, Iraola V, Estupinan M, Fernandez-Caldas E: Sensitization and exposure to house dust and storage mites in high-altitude areas of Ecuador. Ann Allergy Asthma Immunol 2006;97:532-538.

12 Walshaw MJ, Evans CC: The effect of season$\mathrm{al}$ and domestic factors on the distribution of Euroglyphus maynei in the homes of Dermatophagoides pteronyssinus allergic patients. Clin Allergy 1987;17:7-14.

13 Charpin J, Penaud A, Charpin D, Faraj F, Thibaudon M, Vervloet D, Razzouk H: Euroglyphus maynei, étude comparative des réactions cutanées à Marseille et à Briançon. Rev Fr Allergol Immunol Clin 1986;26:117-119.

14 Van Hage-Hamsten M, Johansson SG: Clinical significance and allergenic cross-reactivity of Euroglyphus maynei and other nonpyroglyphid and pyroglyphid mites. J Allergy Clin Immunol 1989;83:581-589.

15 Kemp SF, Lockey RF, Fernandez-Caldas E, Arlian LG: Skin test and crossreactivity studies with Euroglyphus maynei and Dermatophagoides pteronyssinus. Clin Exp Allergy 1997;27:893-897.

16 Mumcuoglu Y: House dust mites in Switzerland. III. Allergenic properties of the mites. Acta Allergol 1977;32:333-349.

17 Arlian LG, Rapp CM, Fernandez-Caldas E: Allergenicity of Euroglyphus maynei and its cross-reactivity with Dermatophagoides species. J Allergy Clin Immunol 1993;91:10511058.

18 Morgan MS, Arlian LG, Fernandez-Caldas E: Cross-allergenicity of the house dust mites
Euroglyphus maynei and Blomia tropicalis. Ann Allergy Asthma Immunol 1996;77:386392.

19 Hill MR, Newton MR, Hart BJ: Comparative IgE responses to extracts of five species of house dust mite, using Western blotting. Clin Exp Allergy 1993;23:110-116.

20 Stewart GA, Bird CH, Krska KD, Colloff MJ, Thompson PJ: A comparative study of allergenic and potentially allergenic enzymes from Dermatophagoides pteronyssinus, D. farinae and Euroglyphus maynei. Exp Appl Acarol 1992;16:165-180.

21 Garcia-Robaina JC, Eraso E, De la Torre F, Guisantes J, Martinez A, Palacios R, Martinez $\mathrm{J}$ : Extracts from various mite species contain cross-reactive and noncross-reactive IgE epitopes. A RAST inhibition study. J Investig Allergol Clin Immunol 1998;8:285-289.

22 Fernandez-Caldas E, Puerta L, Caraballo L, Lockey RF: Mite allergens; in Lockey RF and Ledford DK (eds): Allergens and Allergen Immunotherapy: Subcutaneous, Sublingual, and Oral. Boca Raton, CRC Press, pp 181-201.

23 Thomas WR, Heinrich TK, Smith WA, Hales BJ: Pyroglyphid house dust mite allergens. Protein Pept Lett 2007;14:943-953.

24 Avula-Poola S, Morgan MS, Arlian LG: Diet influences growth rates and allergen and endotoxin contents of cultured Dermatophagoides farinae and $D$. pteronyssinus house dust mites. Int Arch Allergy Immunol 2012;159: 226-234.

25 Yella L, Morgan MS, Arlian LG: Population growth and allergen accumulation of Dermatophagoides pteronyssinus cultured at 20 and $25^{\circ}$ C. Exp Appl Acarol 2011;53:103-119.

26 Yella L, Morgan MS, Arlian LG: Population growth and allergen accumulation of Dermatophagoides farinae cultured at 20 and $25^{\circ} \mathrm{C}$. Exp Appl Acarol 2013;60:117-126.

27 Batard T, Hrabina A, Bi XZ, et al: Production and proteomic characterization of pharmaceutical-grade Dermatophagoides pteronyssinus and Dermatophagoides farinae extracts for allergy vaccines. Int Arch Allergy Immunol 2006; 140:295-305.

28 Brunetto B, Tinghino R, Braschi MC, Antonicelli L, Pini C, Iacovacci P: Characterization and comparison of commercially available mite extracts for in vivo diagnosis. Allergy 2010;65:184-190.

29 Eraso E, Guisantes JA, Martinez J, Saenz-deSantamaria M, Martinez A, Palacios R, Cisterna R: Kinetics of allergen expression in cultures of house dust mites, Dermatophagoides pteronyssinus and D. farinae (Acari: Pyroglyphidae). J Med Entomol 1997;34:684689.

30 Eraso E, Martinez J, Garcia-Ortega P, Martinez A, Palacios R, Cisterna R, Guisantes JA: Influence of mite growth culture phases on the biological standardization of allergenic extracts. J Investig Allergol Clin Immunol 1998;8:201-206.
31 Erban T, Hubert J: Two-dimensional gel proteomic analysis of Dermatophagoides farinae feces. Exp Appl Acarol 2015;65:73-87.

32 Casset A, Mari A, Purohit A, et al: Varying allergen composition and content affects the in vivo allergenic activity of commercial Dermatophagoides pteronyssinus extracts. Int Arch Allergy Immunol 2012;159:253-262.

33 Moingeon P, Batard T, Nony E, Hrabina M, Frati F: Quality control of house dust mite extracts for allergen immunotherapy. Int Arch Allergy Immunol 2013;161:285-286.

34 Casset A, Valenta R, Vrtala S: Allergen content and in vivo allergenic activity of house dust mite extracts. Int Arch Allergy Immunol 2013;161:287-288.

35 Fernandez-Caldas E: Towards a more complete standardization of mite allergen extracts. Int Arch Allergy Immunol 2012;160: $1-3$

36 Kent NA, Hill MR, Keen JN, Holland PW, Hart BJ: Molecular characterisation of group I allergen Eur $\mathrm{m}$ I from house dust mite Euroglyphus maynei. Int Arch Allergy Immunol 1992;99:150-152.

37 Smith W, Mills K, Hazell L, Hart B, Thomas $\mathrm{W}$ : Molecular analysis of the group 1 and 2 allergens from the house dust mite, Euroglyphus maynei. Int Arch Allergy Immunol 1999; 118:15-22.

38 Thomas WR, Smith WA, Hales BJ, Mills KL, O'Brien RM: Characterization and immunobiology of house dust mite allergens. Int Arch Allergy Immunol 2002;129:1-18.

39 Heymann PW, Chapman MD, Platts-Mills TA: Antigen Der f I from the dust mite Dermatophagoides farinae: structural comparison with Der $\mathrm{p}$ I from Dermatophagoides pteronyssinus and epitope specificity of murine IgG and human IgE antibodies. J Immunol 1986;137:2841-2847.

40 Ovsyannikova IG, Vailes LD, Li Y, Heymann PW, Chapman MD: Monoclonal antibodies to Group II Dermatophagoides spp. allergens: murine immune response, epitope analysis, and development of a two-site ELISA. J Allergy Clin Immunol 1994;94: 537-546.

41 Sidenius KE, Hallas TE, Stenderup J, Poulsen LK, Mosbech H: Decay of house-dust mite allergen Der $\mathrm{f} 1$ at indoor climatic conditions. Ann Allergy Asthma Immunol 2002;89:3437.

42 Arlian LG, Morgan MS: Reproductive biology of Euroglyphus maynei with comparisons to Dermatophagoides farinae and D. pteronyssinus. Exp Appl Acarol 2015, DOI: 10.1007/ s10493-015-9882-7.

43 Vidal-Quist JC, Ortego F, Lombardero M, Castanera P, Hernandez-Crespo P: Allergen expression in the European house dust mite Dermatophagoides pteronyssinus throughout development and response to environmental conditions. Med Vet Entomol 2015, DOI: $10.1111 /$ mve.12102. 